\title{
Consumption as extended carnival on Tmall in contemporary China: a social semiotic multimodal analysis of interactive banner ads
}

\section{Dr Zhen Troy Chen}

Assistant Professor in Communication Studies

Department of Media and Communication

Xi'an Jiaotong-Liverpool University, Suzhou, China

ORCID ID: orcid.org/0000-0003-2450-277X

Professor Ming Cheung

Professor and Director

Griffith Centre for Design and Innovation Research

Griffith University, Brisbane, Australia

\section{Recommended citation}

Zhen Troy Chen \& Ming Cheung (2020) Consumption as extended carnival on Tmall in contemporary China: a social semiotic multimodal analysis of interactive banner ads, Social Semiotics, DOI: $\underline{10.1080 / 10350330.2020 .1720992}$

\begin{abstract}
This article examines the multimodalities of banner ads in pervasive marketing and advertising. Departing from the 'Double 11 shopping carnival' spectacle on Tmall, this paper conducts a social semiotic and multimodal analysis of banner ads in the Chinese context. As the investigation of the discursive construction process shows, banner ads in Tmall take advantage of human interactivity, intentionality, persuasion and value creation to increase online sales as part of a gamification process despite the fact that such modalities enhance consumers' shopping experience and sociality. This article provides a synthesis of social semiotics, multimodal analysis and interactivity to guide our analysis of advertising in e-commerce. We argue that apart from traditional marketing strategies, Tmall has extended and obscured the rebellious notion of carnival and used it as a corporation-led strategy to create new cultural forms that encourage spending. This is in line with the rising consumerism in the Chinese society. Our findings will be useful for researchers conducting interdisciplinary studies of multimodal analysis and social semiotics, media and communications as well as advertising and marketing, with a focus on an increasingly globalised China.
\end{abstract}

\section{Keywords}

Social semiotics; multimodal analysis; interactive banner ads; consumption; e-commerce; China

\section{Introduction}

As a medium of communication, advertising plays a crucial role in pervasive marketing for organisations and businesses to build brand image, engage with their targeted audience, and promote their goals and activities (Sifaki and Papadopoulou, 2015). For e-commerce, advertising is particularly aimed at turning attention into transactions. Of the various types of advertisements (ads), 
website banner ads are an important genre. They are placed at a prominent position of a website or mobile app to attract consumers' attention during their first visit, in accordance with web design and search engine optimisation (SEO) practices. Unlike traditional advertising, which is usually promoted through third-party intermediaries such as traditional mass media or new social media, banner ads within e-commerce websites directly function as a directory and touchpoint for consumer navigation. They are an effective tool to target consumers for boosting sales and consumer spending. This is in line with the concept of 'e-selling', which is different to e-commerce or e-retailing in that it has a more nuanced focus. E-selling is a new term intended to conceptualise human-computer dialogue 'characterised by the digital spatio-temporal locus, the psychology of online persuasion, and complex perceptions of value' (Parvinen et al., 2015: 214). It is closely linked to concepts such as human interactivity, intentionality, persuasion and value creation, for which banner ads play a prominent role.

In this article, we examine a selection of banner ads on Tmall designed to attract consumers' attention through gamification design following the annual online shopping carnival on Alibaba's e-commerce platforms. Gamification design has been experimented by retailors, a practice of creating a game around the shopping experience, for example, to collect coupons and stamps (see more in Frith, 2013; Parag et al, 2013). Tmall, Tianmao, literally Sky Cat, is 'China's largest third-party platform for brands and retailers' and is owned by the Alibaba group. It was originally named Taobao Mall or Taobao Shangcheng (Alibaba, 2017a). It is a business-to-consumer (B2C) web domain launched in 2008, parallel to Alibaba's consumer-to-consumer (C2C) platform Taobao. Tmall has achieved a $136 \%$ year-on-year increase in cross-border retail revenue and remains the number one e-commerce platform in terms of market share (Alibaba, 2017b). CIW (2018) reports that the listing of more than 16,400 international brands from 68 countries on Tmall has attracted more than 529 million mobile Monthly Active Users (MAUs). Tmall now occupies almost 60\% of the Chinese B2C market sales in fashion and apparel, and maintains steady growth in consumer electronics and fast moving consumer goods (FMCG). A particularly significant figure is connected to the $11^{\text {th }}$ of November (Shuang 11, or Double 11), known as Singles' Day (Meng and Huang, 2017). Tmall generated over USD 30.8 billion in just 24 hours in 2018 (see Figure 1, Alizilia, 2018). Together with Alibaba's offline infrastructure (Yintai Mall and unmanned supermarkets), cloud computing (Ali Cloud), payment (Alipay) and logistics (Cainiao Yizhan Delivery), Tmall has made a huge global impact in e-commerce consumption with its well-rounded industry ecosystem. 


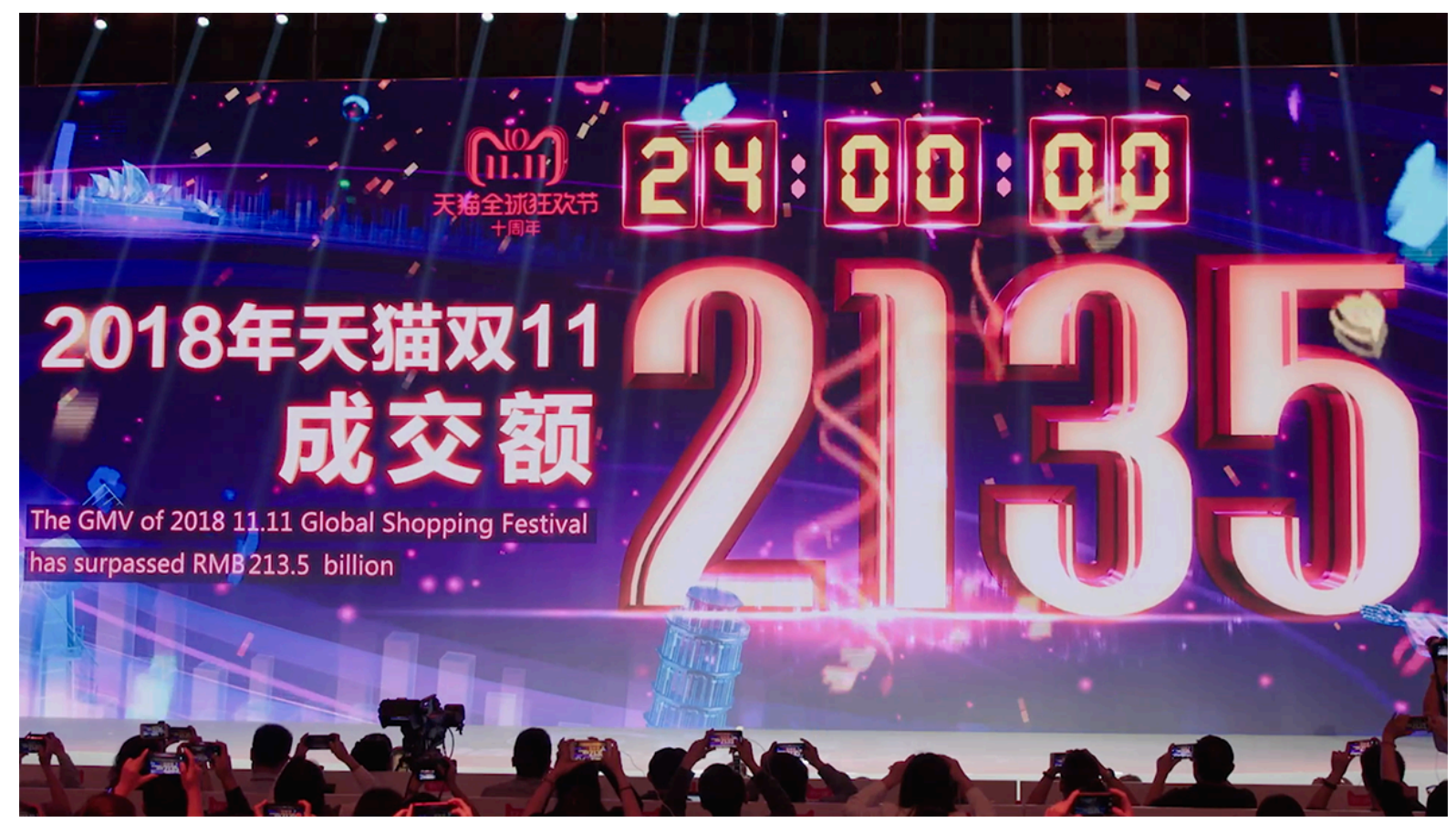

Figure 1. Live grand celebration of Double 11 Carnival (Alizilia, 2018)

A brief review of the development of Tmall and Alibaba gives a general idea of China's changing economic landscape since its opening-up reform from 1978. Consumerism has taken root in Chinese society in both a top-down and bottom-up fashion. Following Deng Xiaoping's approval of 'let[ting] some people get rich first', China has adopted a socialist market economy with a radical privatisation process while keeping various modes of ownership (state and private). The country has integrated with the world at different levels in the globalisation process, exemplified by its accession to the World Trade Organisation (WTO) in 2001. As the second largest economy measured by Gross Domestic Product (GDP), in 2013 China also became the second largest online retail market after the United States (MGI, 2013). As Hulme (2014: xxiv) notes, the Chinese government has launched various 'vigorous' campaigns to encourage spending to achieve a xiaokang society as an important pillar to boost the domestic economy. Xiaokang is a Confucian term referring to a society of modest means. It is not against economic growth in that it provides prosperity on the condition that the prosperity is widely distributed. The concept of xiaokang was re-appropriated by Deng Xiaoping as the goal of Chinese modernisation and is being used by the government even to this day. It is an important step for China to be part of the consumer society, transforming from an investment-led economy to a domestic consumption-based one (People's Daily, 2018). However, with China's vast landmass and imbalanced regional development, there are constant contradictions between the Western concept of consumerism (individual-based) and consumerism in China (mutual-based). It is arguably unique in the sense that it is government-engineered and emerged within a capitalist-socialist model. Many scholars have examined the consumer behaviour and identity of China's middle class (Wang, 2014) through their consumption of commodities and cultural products (see a collection of 
relevant essays in Hulme, 2014). Commentators and journalists alike criticize China as a country where 'everything is up for trade' (see for example, $\mathrm{Xu}, 2007$ ), while some scholars argue that contemporary Chinese are more focused on individualism and personal desire beyond the government's control. At the same time, consumerism challenges the social norms inherited from the Confucian legacy (Rofel, 2007).

This article investigates banner ads on Tmall with a social semiotic and multimodal analysis approach under the backdrop of the proliferation of online consumption on Tmall. This multidisciplinary article contributes to the growing literature on multimodal semiotic analysis with a 'glocal' perspective. We articulate the obscured notion of Bakhtin's carnival/carnivalesque (1984) as non-violence resistance towards control, in this case, consumerism (see more, Prendergast, 2019). The notion is obscured in the case of Tmall in the sense that it is corporate-engineered. It is not used to resist consumerist ethos, rather it is used creatively by Tmall to boost sales, creating a playful and gamification atmosphere. This carnivalesque started ten years ago as a binge consumption spectacle in China. The celebration does not stop after the Double 11 Carnival. As we will show below, it penetrates consumers' daily consumption on this e-commerce platform. In sum, we argue that the rebellious carnivalesque has been captured by consumerism in contemporary China, where consumers use carnival not to resist capitalist control but rather to consume as in a game. It is a spectacle celebrated by the platform, endorsed by the government and participated by consumers. Figure 1 shows every year Alibaba organises a grand live show and conduct the 24-hour countdown to see how much money it makes during the carnival.

\section{Literature review}

Our research focuses on the banner ads of Tmall, which are multimodal. Banner ads make and convey meaning through the combination of textual, audio-visual and interactive modalities (virtual reality, clicks and hyperlinks, thus hypertextuality), all in one entity. We first follow the work of social semiotics and multimodality, which hold that semiotic resources such as signs and codes (in the form of language or visual images) are socially constructed (O'Halloran et al., 2011; Kress and Van Leeuwen, 2006). These conventions in the form of language and visual images are not static. They are subject to change and transformation, and should be understood in specific social and cultural contexts. The underlining theoretical rationale is that meaning-making and discursive processes with the help of semiotic resources are shaped by the motivations and interests of the sign-maker (He, 2017). However, we know little about the discursive constructions that aim to persuade consumers and change their minds (Van Dijk, 1993). This is particularly the case for the process of discursive construction in post-reform China after 1978, where consumerism is on the rise yet seldom investigated with a perspective of multimodal analysis. In the case of Tmall, the motivation and interests of the sign-maker can be investigated through a social semiotic and multimodal analysis of 
the banner ads. In addition, because these banner ads are situated within an e-commerce website, we also investigate the hypertextuality and affordances as part of interactive modalities that facilitate the discursive process in the form of digital and multimedia texts. Here, we focus on the two-dimensional aspects of the banner ads as interactive signs and sites, a departure from traditional multimodal analysis. In the banner ads, hypertextuality is achieved through the affordances of digital text (search, scan, click and tap). This interactivity allows and enables consumers to travel between texts and pages through hyperlinks and interactive functions. Informed by Adami's semiotic analysis of website interactivity, we aim to examine the interactivity of the banner ads as both signs and sites (the twofold nature in Adami's term, 2015), in addition to the textual effects achieved through various traditional textual forms. Thus, in addition to traditional textual forms such as still and dynamic images, design and words, we also investigate affordances available to activate interactivity. To do that, we adopt and extend Halliday's (1978) three metafunctions (the ideational, interpersonal, and textual) to analyse the above two sets of objectives, both the (previously static) discursive process and the now interactive banner ads on e-commerce websites.

In advertising and marketing research, discourse analysis guided by metafunctions has been widely used to study information and persuasion conveyed via a diversified range of texts (Wagner, 2015). The first strand of work is centred on language and text. In recent years a visual turn has occurred, as identified by a number of scholars in advertising (see a review in Holsanova, 2012). Following this visual turn, a growing body of interdisciplinary literature uses social semiotics and multimodal discourse analysis to study a number of advertising and media formats (Thomas, 2014; Holsanova, 2012). These include food and product packages (Wagner, 2015), magazines (Lick, 2015; Chen and Machin, 2014), posters (Sifaki and Papadopoulou, 2015; White, 2010), picture books and animated movies (Unsworth, 2015), photography on social media (Zappavigna, 2016), automobile commercials (Chen, 2016), website and TV ads/reviews (He, 2017; Adami, 2015; Jessen and Graakjær, 2013), café design and architecture (Aiello and Dickinson, 2014), as well as political speech and presentation (Wong, 2016), to name just a few. Against this backdrop, we champion a tri-fold convergence of the multimodality of texts, visuals and affordances (interactivity) and use it as a framework to guide our analysis.

\section{The social semiotic framework of interactive banner ads}

The texts, visuals and affordances of banner ads all contribute to the meaning-making process on Tmall. This is in line with social semiotics which regards codes of language and communication are shaped by social and cultural processes. In this article, we are particularly interested in visual communication, that is, how the producer, mediator/interpreter and audience/consumer are connected through banner ads. There are a few theoretical approaches to this, for example, the semiotic and cognitive approach. The semiotic approach focuses on visual segmentation as a result of 'intentional, 
socially typical choices that are made to achieve the optimally desired communicative effect on a hypothetical model reader/viewer', whereas the cognitive approach treats the dynamic and engagement process between the audience and the visuals as a point of departure from a reception perspective (Boeriis and Holsanova, 2012: 263). The distinction between the production and reception studies shows that the semiotic approach focuses more on the factors that can shape perception and segmentation process as a shared knowledge, whereas the cognitive approach investigates the general and individual patterns that unfold in the actual reading of such constructed discourses. How consumers actually engage with various banner ads (subjectivity and agency) is out of the scope of our study. At the outset, the trifold approach we take in this study is semiotic in nature. In fact, such an approach is widely used in investigating the socially and culturally entangled semiotic system (see Kress and Van Leeuwen, 2001). This strand of work focuses more on the construction and communication processes (and their effect) than on individual preferences. However, both approaches value the principles of perception structure and organisation of textual and visual resources, in a predicted and interpretative manner. Therefore, in analysing banner ads, our study will particularly look at the structure and organisation of the multimodal resources of interactive banner ads. In doing so, it allows us to investigate these resources from three levels, namely the macro (ideological), the meso (organisational) and the micro (semiotic) level of shared social and cultural contexts in China. This is in line with Foucault's theory that places interaction and communication under specific powerknowledge regimes (Da Conceição Pereira, 2016).

\section{Contextualise the three metafunctions with interactive affordances}

In this section, we look at existing literature about how multimodal discourse analysis is incorporated with such an approach to study both the textual and visual resources of advertising and digital marketing. Multimodal analysis can be traced back to Halliday's $(1978,1994)$ Systemic Functional Linguistics (SFL), which is used to study the "functional and situational organisation of language in the social context' (He, 2017: 171). As a 'functionalist', Halliday regards 'language as a device designed for accomplishing communicative ends, and insofar as function the basis for his description of language' (Urban, 1981: 660). At the outset, Halliday (1978) views linguistic signalling as an intersubjective phenomenon. Therefore, he contends that language study should begin with discourse analysis (linguistic signalling in action). As language users also encode individual and multiple layers of meaning within a given discourse, the distinct functional modes must be analysed. He suggests that the discourse is constructed by the intertwined meaning and function. He then develops three abstract metafunctions (ideational, interpersonal, and textual), a framework that can be mapped onto a given discourse, textual, visual or both. First, the ideational function is to say something about the world, referring to particular 'objects, people or even ideas' for a given socio-cultural group (Sifaki and Papadopoulou, 2015: 473). Second, the interpersonal function is to say something about the actors who participate in the communicative process. Finally, the textual function focuses on the text as a 
whole. Another important component of this framework is 'contextualism', that is, to view language use in relation to both linguistic and non-linguistic contexts (Urban, 1981).

Drawing on Halliday's SFL, Kress and Van Leeuwen (2006) adapt the metafunctional theory to study multimodal visual communication in the face of the visual turn (He, 2017: 171). They have developed a theoretical framework called Visual Grammar (VG), mirroring and naming Halliday's three functions as Representational, Interactive and Compositional meanings. They suggest that visual communication is a semiotic mode of its own kind. Therefore, the three metafunctions can also be applied in visual communication. In doing so, VG provides new terms as 'grammatical realizations of metafunctional meaning in visual social semiotics' (Boeriis and Holsanova, 2012: 265). This is particular useful in our case of analysing interactive banner ads. Representational meanings follow the ideational function, unfolding 'actions and events, processes of change, transitory spatial arrangements' (Kress and Van Leeuwen, 2006: 56). Interactive meanings are coordinated via a number of interpersonal systems: gaze, social distance, perspectival angle, and modality.

Compositional meanings at the textual level are achieved by leveraging resources such as information value, framing, and salience. Lemke (2002) further develops three equivalent terms, Presentational, Orientational, and Organizational, to analyse hypermodality, whereas Adami (2015) follows the terms in VG, adding an additional Logical function. Here, to study the interactivity together with the multimodal VG of e-commerce banner ads, we stick to the terms of Halliday as refined by Adami to avoid the possible confusion of an 'interactive' function with different connotations and theoretical underpinnings (see detailed discussions in Adami, 2015). As shown in Table 1, we present the refined framework for the investigation of interactive banner ads on Tmall to achieve both description and evaluation to avoid turning our analysis into mere description of the banner ads.

Table 1. Axis of Metafunctions and the two dimensions of interactive sites/signs, adapted from Adami (2015: 142)

\begin{tabular}{l|l|l|l|l}
\hline Dimensions & $\begin{array}{l}\text { Ideational } \\
\text { Function }\end{array}$ & $\begin{array}{l}\text { Interpersonal } \\
\text { Function }\end{array}$ & $\begin{array}{l}\text { Textual } \\
\text { Function }\end{array}$ & $\begin{array}{l}\text { Interactive } \\
\text { Value }\end{array}$ \\
\hline $\begin{array}{l}\text { Syntagmatic } \\
\text { (within the page) }\end{array}$ & $\begin{array}{l}\text { what it is: } \\
\text { form/meaning } \\
\text { (representation of } \\
\text { the world) }\end{array}$ & $\begin{array}{l}\text { what it says about: } \\
\text { authors and users }\end{array}$ & $\begin{array}{l}\text { how/where } \\
\text { on the page: } \\
\text { salience; } \\
\text { information } \\
\text { structure }\end{array}$ & $\begin{array}{l}\text { aesthetics of } \\
\text { interactivity }\end{array}$ \\
\hline $\begin{array}{l}\text { Paradigmatic } \\
\text { (optional } \\
\text { realization) }\end{array}$ & $\begin{array}{l}\text { which action; } \\
\text { which effect; } \\
\text { where }\end{array}$ & $\begin{array}{l}\text { directionality/ } \\
\text { power: who } \\
\text { towards whom } \\
\text { authors/users/others } \\
\text { given-new }\end{array}$ & $\begin{array}{l}\text { functionalities of } \\
\text { interactivity }\end{array}$ \\
\hline
\end{tabular}

In Table 1, we synthesise the framework adapted by Adami with SFL and VG to analyse the source 
text in two dimensions, namely, the syntagmatic dimension and paradigmatic dimension. The synthesis is useful for explaining the two dimensions (space and time) of interactive banner ads on top of SFL and VG: (1) the spatial dimension of an ad, for example, where it sits on the page, and how a sign is made up of multimodal texts; (2) the intertextual dimension, which works as a gateway for realisation of potential meaning-making through specific functions such as clicks, hovering, searching and sharing (Adami, 2015: 140). These two dimensions will guide our analysis given the twofold nature of interactive banner ads as both signs (forms of meanings) and sites (for actions to produce certain effects).

Table 1 illustrates how the three metafunctions are mapped with the two dimensions mentioned above, creating an axis of meaning-creation. Syntagmatically, an ad contributes to the ideational function capable of presenting the world with various arrangements. Paradigmatically, it contributes to activating potential meanings through various inflections and actions. In terms of the interpersonal function, syntagmatically, it communicates to the users with diversified expectations.

Paradigmatically, it sets the directionality within a connection, a power-knowledge regime built between the authors and users (who acts upon whom). As for the textual function, syntagmatically, it concerns the structure of the information and its value created by the ideational and interpersonal function of the text as a whole. Paradigmatically, it relates to the time-space pair of interactive banner ads as both signs and sites, mapping the two dimensions in a before-after relationship within a certain change. That is, the text that is given as it is and the text it becomes if activated. These two dimensions (syntagmatic and paradigmatic) mark two distinct yet relevant processes on a continuum: one is the arranging process of the texts, images and affordances (for interactivity) of the banner ads (once activated); the other is the completed arrangement and layout, an equilibrium presented as the banner ads in a static state.

As we will demonstrate in our analysis section, the syntagmatic dimension (ideational, interpersonal, and textual) guides our interpretation of interactive banner ads as signs in a relatively static way (compared to 'sites' to be activated). In turn, the paradigmatic dimension guides our analysis of the interactivity to be activated in a more dynamic way. That is, the interactive affordances are designed to achieve interactivity with certain effects through consumers' actions to make the meaning-making process complete.

\section{Methodology}

Following the theoretical framework developed above, we use a combination of the textual, visual and interactive analysis of the banner ads on Tmall as our primary methodology. We select banner ads in Tmall for its Double 11 Carnival 2018, as well as other banner ads as an extension of the carnival metaphor. As it is not our aim to conduct a reception study or to validate the effects of designated design campaigns, the eye-tracking method (Boeriis and Holsanova, 2012) or retrospective interviews 
(Gidlöf et al., 2012) are not used. The detailed working process of semiotic and multimodal analysis involves an 'analytical zoom' in and out of the banner ads being examined (Boeriis and Holsanova, 2012: 264). We then regard the zoom levels as a point of departure to closely investigate elements of each ad with the guidance of VG. These include images, texts, fonts, colours, and the ad as a whole (the relationships between the various elements will be explained in detail during analysis). We then put the ad in the wider social and cultural context with the message that it is designed to convey, zooming out from the separate and segmented clusters of elements to the comprehensive and interactive view of the ad as a whole again. As we merely aim to explore the production aspect of banner ads, these methods are deemed sufficient because they have proven fruitful in a number of social semiotic studies (Chik and Vásque, 2017; McVee and Carse, 2016; Grumbein and Goodman, 2015; Feng and Wignell, 2011; Tan, 2010).

\section{Data analysis}

As indicated in Table 1, the syntagmatic dimension utilises several modes of textual and visual semiotics to fulfil the ideational, interpersonal and textual functions, whereas the interactive value is achieved through the paradigmatic dimension with affordances of intertextuality and interactivity. These two dimensions will be in turn analysed in conjunction with the multiple banner ads. At the outset, these two dimensions often work together in digital and multimedia environments. It is hard to separate them, even within one banner ad. Therefore, it makes sense to analyse these two dimensions together as a whole and as a complete process. However, to test our proposed framework, we have to separate and analyse them respectively at a later stage to achieve better clarity. 
TMALL天猫

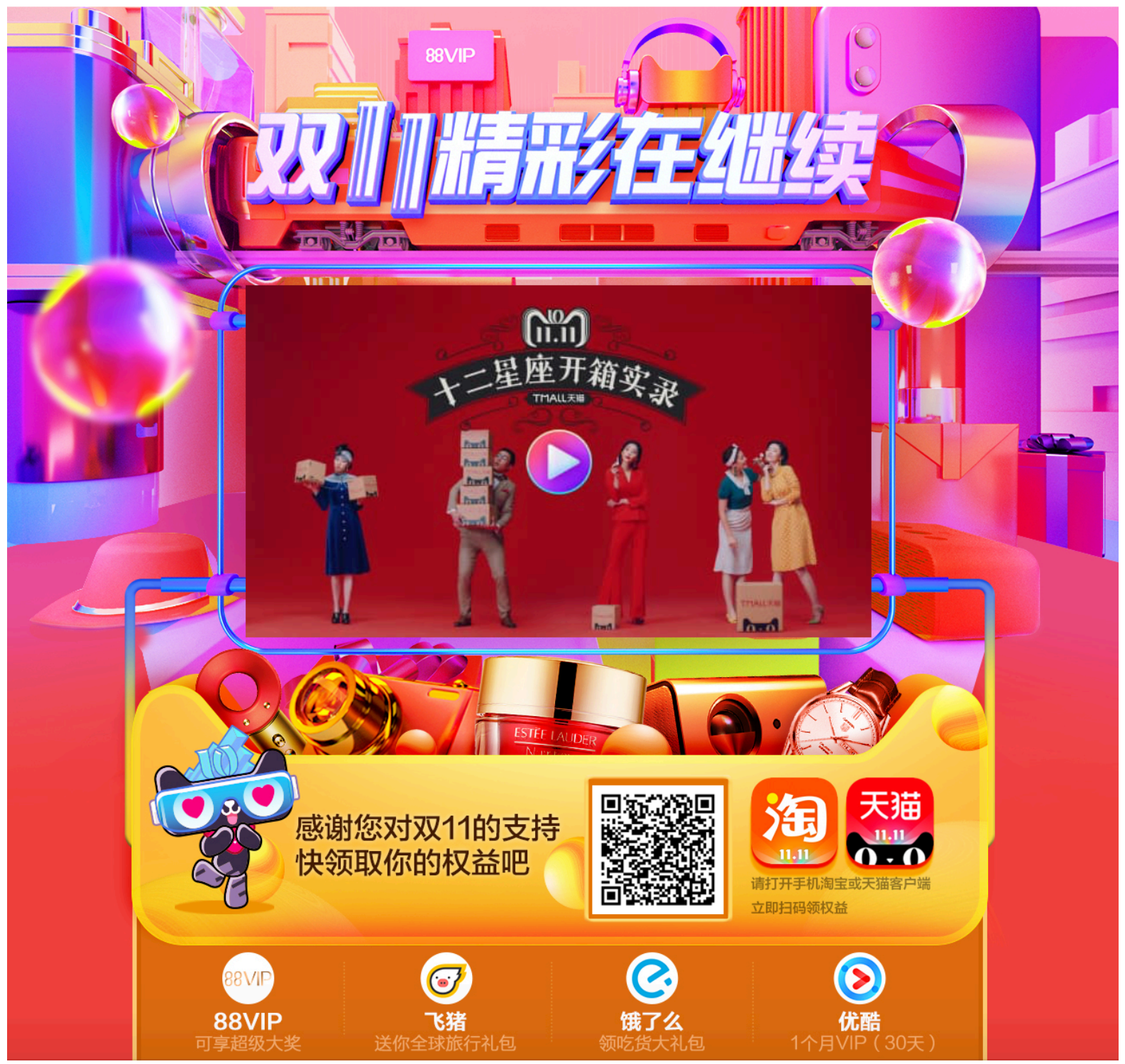

Figure 2. Banner ads on Tmall's landing page 2018

That said, we first take a holistic view in analysing both dimensions with the banner ad in Figure 2.

For the ideational function, this ad shows the Double 11 Carnival is on. It also provides a video depicting the myth of the traits of twelve constellations and how consumers respond when getting their parcels delivered from the carnival. It is extremely simple in terms of design as the concept and navigation of Double 11 Carnival is well known in China. As stated at the beginning, we argue that the celebration of carnival and gamification has extended to everyday consumption on Tmall as an organisational marketing strategy. We will first look at two banner ads of Double 11 Carnival 2018 (Figure 3) and then further look at other banner ads in Figures 4-6 in everyday scenarios. 

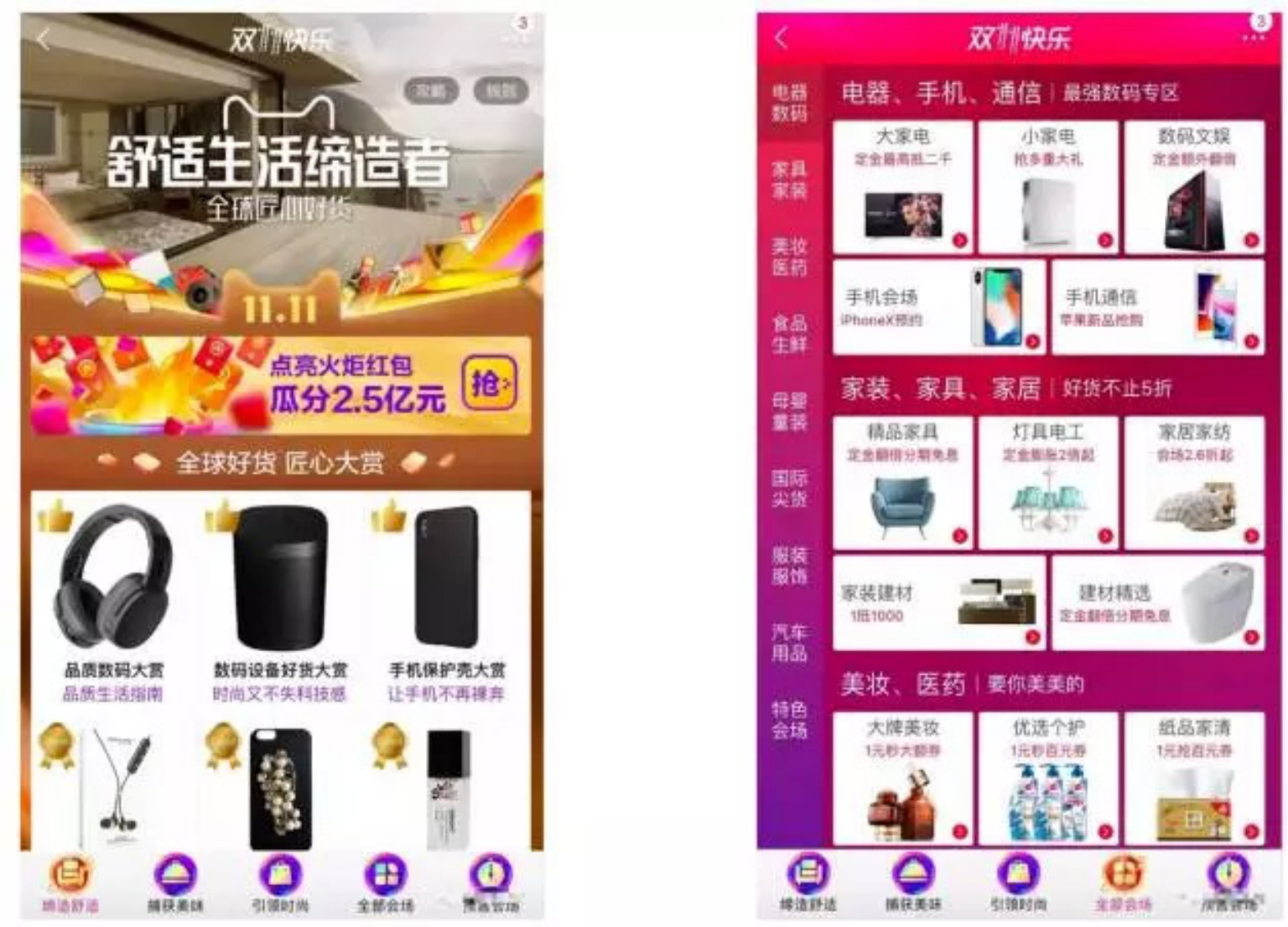

Figure 3. Banner ads of Double 11 Carnival 2018

According to Chen (2017), Tmall ran a number of pre-carnival campaigns to attract consumers' attention and engagement (see Table 2). In 2018, Tmall used the gamification design of spreadable red envelopes worth RMB250 million to encourage sharing through digital word-of-mouth. In Figure 3 , the key message is that Tmall is a creator of comfortable life. The Cat-shaped icon is marked with 11.11 as the nose and eyes of the Sky Cat (Tmall). The cat stretches its two arms, embracing a banner ad with multiple 'red envelopes' indicating good fortune, money and coupons on offer during the carnival. Through such campaigns, we can understand that gamification design plays an important role in promoting Tmall's annual Double 11 Carnival. It has been widely deployed into after-carnival operation which we termed as 'extended carnival' in everyday online consumption in China. 
Table 2. Tmall pre-carnival campaigns 2017, adopted from Chen (2017)

\begin{tabular}{l|l|l|l}
\hline Campaigns & Timeline & Events & Type \\
\hline $\begin{array}{l}\text { Red envelope- } \\
\text { torch relay }\end{array}$ & 19 Oct -10 Nov & $\begin{array}{l}\text { Invite friends to click and sign up } \\
\text { through various social media to } \\
\text { share the red envelopes. }\end{array}$ & Red envelopes \\
\hline Pre-paid orders & 20 Oct -10 Nov & $\begin{array}{l}\text { Prepayment, securing chosen } \\
\text { goods, pre-delivery (with } \\
\text { anticipated delay in delivery based } \\
\text { on past experience). }\end{array}$ & Pre-payments \\
\hline $\begin{array}{l}\text { Coupons and } \\
\text { discounts }\end{array}$ & 20 Oct -11 Nov & $\begin{array}{l}\text { Store/brand-specific coupons and } \\
\text { discounts. }\end{array}$ & Discounts \\
\hline $\begin{array}{l}\text { Huabei lucky } \\
\text { draws }\end{array}$ & 21 Oct -10 Nov & $\begin{array}{l}\text { Deals of more than RMB200 each } \\
\text { will bring a lucky draw opportunity } \\
\text { for a free deal up to RMB4999. }\end{array}$ & Lucky draws \\
\hline $\begin{array}{l}\text { Group red } \\
\text { envelopes }\end{array}$ & 25 Oct -11 Nov & $\begin{array}{l}\text { Create social media groups, } \\
\text { accumulate impact to get further } \\
\text { discounts. }\end{array}$ & Red envelopes \\
\hline Cat hide-and-seek & 26 Oct -11 Nov & $\begin{array}{l}\text { Red envelopes worth RMB50 } \\
\text { million will be distributed on } \\
\text { Double 11. Golden Cats will } \\
\text { randomly appear in 50 product and } \\
\text { service categories, with the smallest } \\
\text { red envelopes worth RMB100 each. }\end{array}$ & Red envelopes \\
\hline
\end{tabular}

The three banner ads in Figures 4-6 present the goods on sale with instructions and invitations. For instance, the text 'shop now' together with product images achieves its overarching ideational function, that is, to tell consumers that they are ads, selling FMCG (Figure 4), mooncakes (Figure 5) and tailor-made outfits (Figure 6), respectively. The 'telling' process is the interpersonal function in action, with ads, designers and consumers already established within a communication and meaningmaking process. For the textual function, these ads are placed at the top of the page to increase salience. These three metafunctions are achieved through a combination of multimodalities, involving texts, images and icons. In addition, the intertextual dimension is achieved through interactive affordances such as scrolling gadgets and links (clickable text together with text boxes) for interactivity, providing a gateway and site for the realisation of potential meaning-making and actions. Putting together, these banner ads not only work as signs, but also sites, as the twofold nature discussed in the literature review section. In the following two sections, we will zoom in and analyse the syntagmatic and paradigmatic dimensions, respectively.

\section{The syntagmatic dimension under the framework of $V G$}

Colour. Colour is associated with effects and functions as a communicative carrier and vehicle. Van Leeuween (2011) points to two important functions of colour: identity and textual meaning. For identity, colour can be associated with a certain brand or a product that the banner ad is advertising. For example, in Figure 4, the Snickers chocolate product is recognised immediately because of its 
brown packaging. Fulinmen (福临门, literally, blessing comes to your doorway), positioned on the left in Figure 4, is a brand of rice in China. For textual meaning, colour has an ability to convey structure of an ad (its coherence and overall 'feeling'). By using light green, Fulinmen tries to create a brand image associated with nature to signify that it is healthy, organic and environmentally friendly. The Chinese character 福 (fu, meaning blessing) is in gold to express prosperity and glory. The chocolate Snickers (brown) and the AXE cleanser essence (made of lemon extract) are in their 'natural' colours to deceive and persuade consumers to believe that 'what you see is what you get'. As mentioned previously, Tmall has various campaigns held during festivals (such as Mid-Autumn Festival, Mother's Day, and Christmas) beyond its self-created Double 11 Carnival for Singles' Day. Colours are tailored for different festivals to celebrate a certain festive mood. For example, despite the fact that red is deemed alarming and aggressive in certain cultures, it is widely used in China, particularly during Spring Festival and weddings. It is believed that red discourages bad luck and evil spirits, thus bringing blessings and happiness. Figure 5 uses red, golden and pink to create a festive mood for the Mid-Autumn Festival. In particular, red is used for the characters of 抢100元优惠券 (to snatch the RMB100 coupons). It makes the 'instruction' stand out from the already crowded space of an ad full of symbols and texts in large font. In comparison, the banner ad in Figure 6 uses black to represent premium products (the text indicates premium and tailor-made female outfits) and therefore coupon and low-price strategies do not apply. Similarly, as presented in Figure 7, the ad on the left advertising an automobile uses blue to signify trustworthiness.

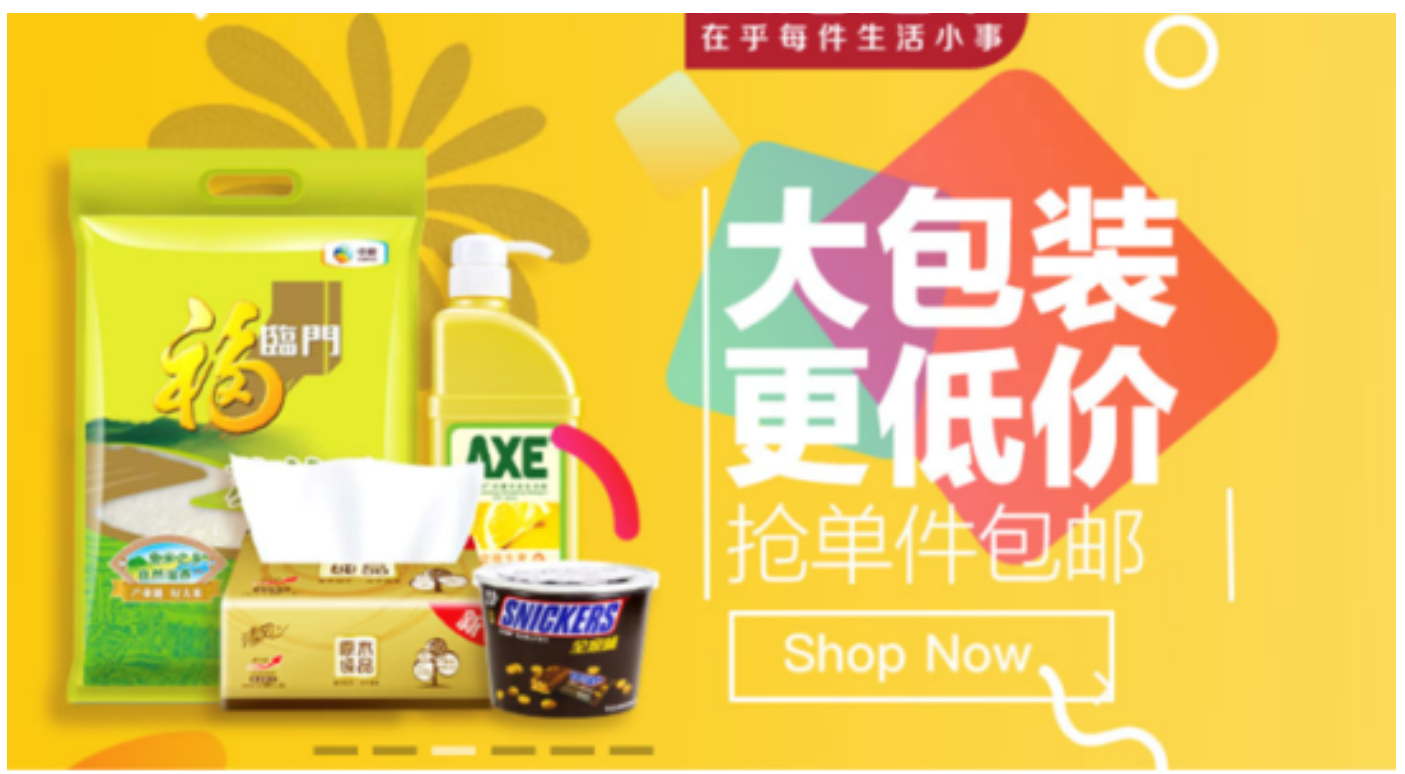

Figure 4. Banner ad promoting FMCG and snack 


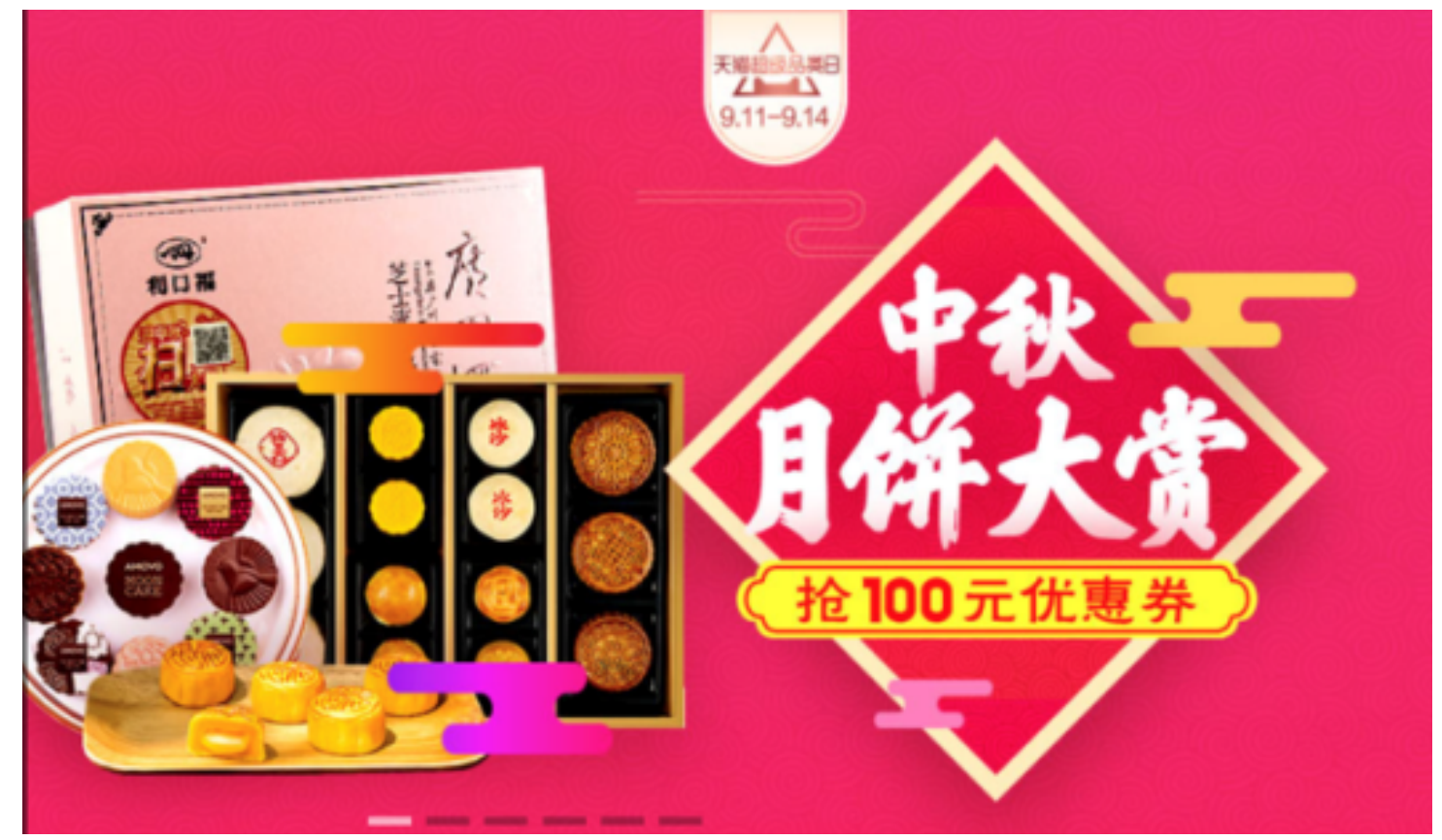

Figure 5. Banner ad promoting mooncakes

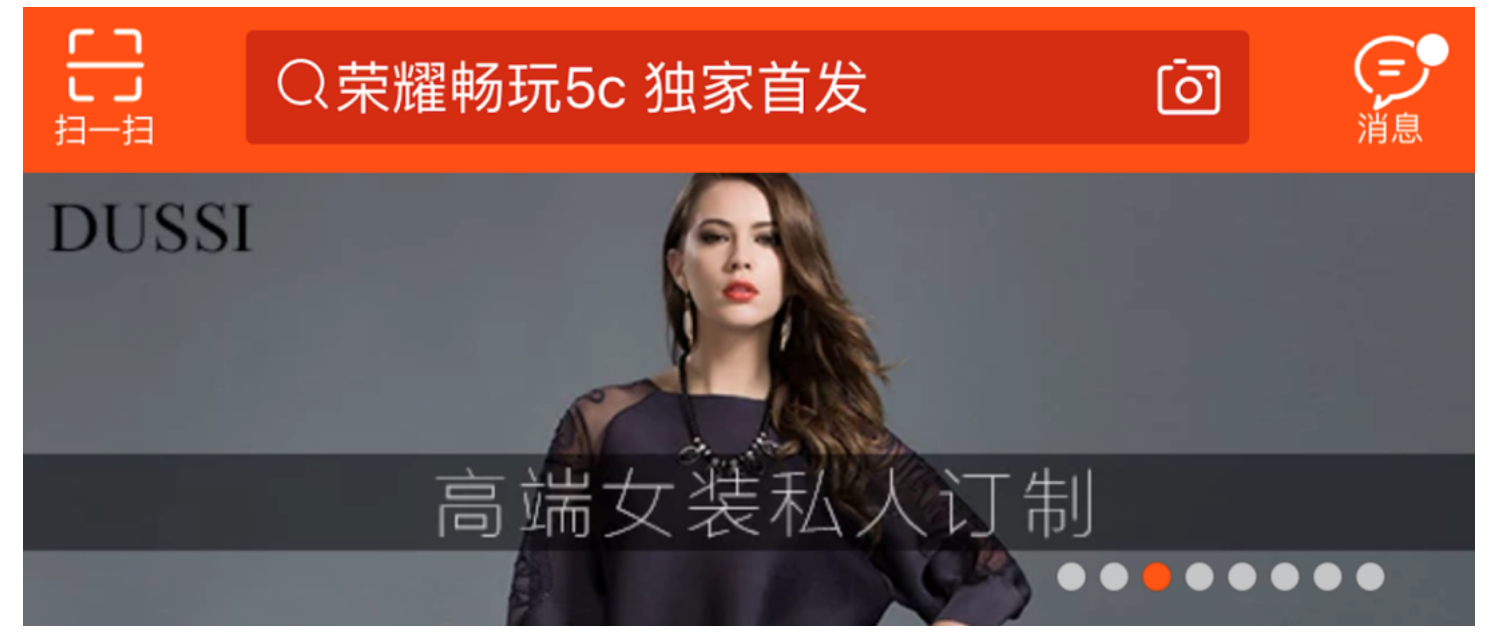

Figure 6. Banner ad promoting a tailor-made outfit

Text. Text includes brand name (the actual name including the logo), basic information about a certain product, and most importantly, storytelling. Because text is one of the most conventional modes used in advertising and many studies are dedicated to it, we will not conduct detailed textual analysis for banner ads here. The general observation is that banner ads on Tmall rarely use a storytelling approach as they predominately use text as instructional information. This is often pricerelated, for instance 'to snatch red envelopes and coupons', 'it is cheap now' and 'if you love your mom, dress her up like this' (see Figure 7).

Typography. Typography is closely related to text. Some typography is meant to be decorative. Chinese calligraphy, for instance, is deemed a form of art in itself. Other types are mundane to 
indicate mandatory information (some of the banner ads explicitly write 'advertising'). Typography is a useful device to achieve evocativeness and can contain rich connotations and metaphors (Kress and Van Leeuwen, 2006). Figures 4-6 illustrate how different typographies are used for different occasions. The ad in Figure 4 uses a computer-enabled art font that is both functional and decorative, while for a traditional Chinese festival the ad in Figure 5 uses Chinese calligraphy, which adds a cultural touch to create a positive association within the Chinese market.

Imagery, symbols and icons. These include both information or non-informational elements within a banner ad. These elements are first of all ideational, to show consumers what the ads are promoting. They are also interpersonal. For example, for human figures (Figure 6 and the ad on the right in Figure 7), two unknown models rather than celebrities are presented. The 'mom' in Figure 7 directly connects herself to the consumers through her gaze. According to Kress and Van Leeuwen (2006: 117), this is a 'demand' (compared with an 'offer'), where represented participants look at the viewers/consumers. Through such an image, the producer of the ad (Tmall) also does something to the consumers. The gaze and gesture of the represented mom 'demand' the recipients/consumers to create an imaginary relationship. This relationship is in turn intended to arouse certain reactions on the part of the consumers (Kress and Van Leeuwen, 2006: 117-118). In Figure 7, the mom looks directly at the consumers with an elegant smile on her face. Her gaze, smile and gesture (presenting a bracelet) are aimed at establishing a relationship with the consumers and thus garner favourable attitudes towards her and, more importantly, the outfit and bracelet. If we zoom out to investigate the textual or compositional function of this ad, it uses the golden colour to signify prosperity and festive mood of Mother's Day as a whole. Zooming in again, a cluster of the model, outfit and background imagery such as flowers are also worth exploring. The flower presented is a peony (mudan), the national flower of China, signifying prosperity and blessing. In Figure 6, the ad uses a low angle where the model looks down on consumers, creating a symbolic power over them. The power within such an interpersonal relationship derives from the fact that the model presents fashion outfits and premium tailor-made services to consumers.

Graphic devices such as abstract lines and shapes are also used. These devices are non-informational as symbols or icons per se. However, with some appropriation or arrangement, they can convey certain meanings. For example, for automobile ads (left, in Figure 7), the variation that makes the background of the car blurred is intended to signify speed and dynamics.

The above analysis has demonstrated how multimodal analysis can be conducted across the various modes of Tmall banner ads including colour, text, typography, and imagery. At the same time, the analysis has been conducted at different levels (zooming in and out) to focus on specific elements and clusters following the ranking mechanism of the whole, group, unit and component (Boeriis and Holsanova, 2012: 262-265). 


\section{The paradigmatic dimension on interactivity}

The second part of the analysis is devoted to the investigation of the interactivity and its associated interactive meanings of banner ads. Interactivity is defined as the affordance of a text with multimodality to be acted upon, realising the full capacity of hypertexuality, and thus meaningmaking. As for banner ads, the meaning-making process is embedded in the affordance of interactivity to make consumers' consumption easier and playful (gamification). In doing so, a symbolic and discursive process is used to boost sales and it also contributes to the cultivation of a materialist and consumerist culture in contemporary China.

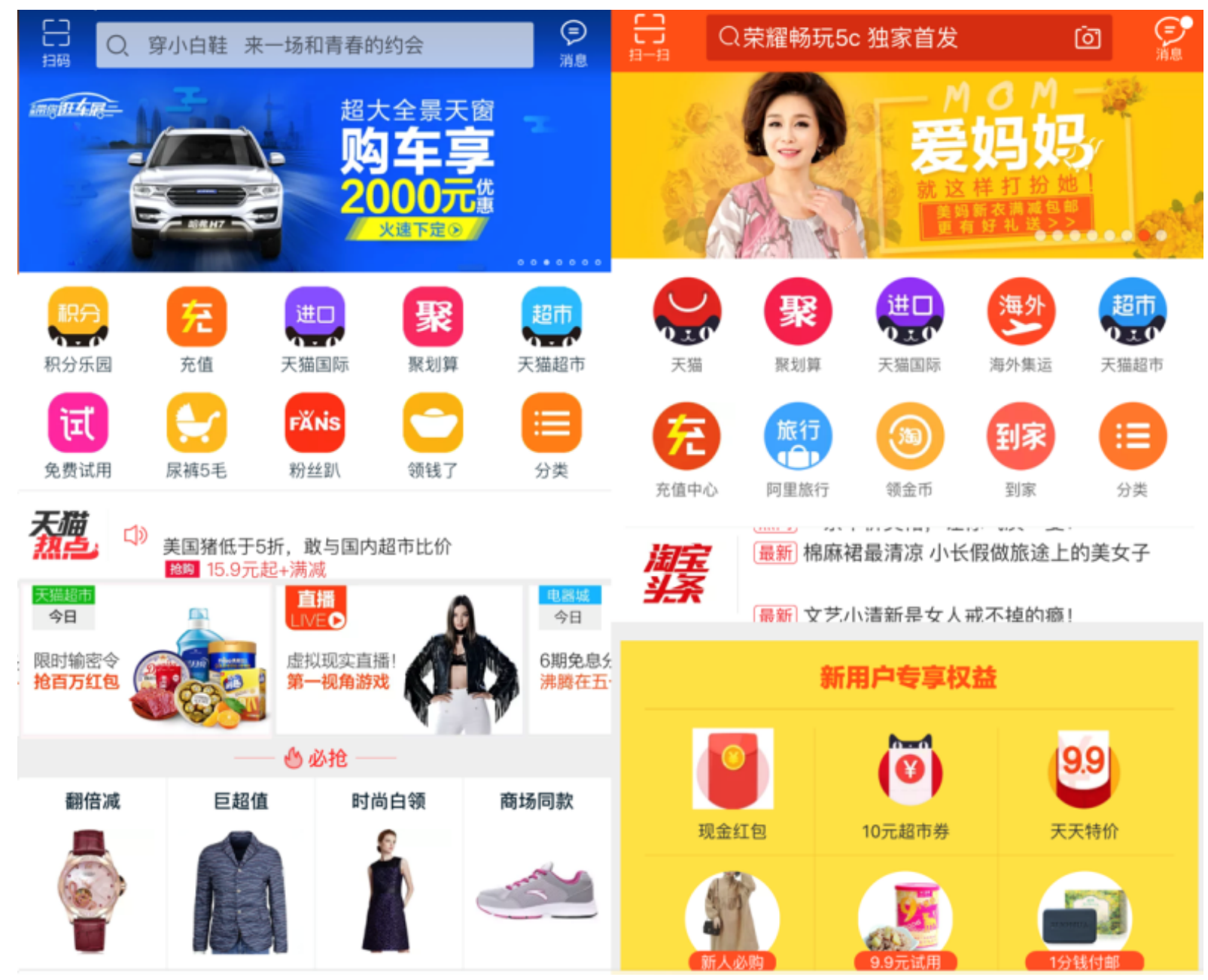

Figure 7. Tmall banner ads with interactive functions advertising automobile (left) and Mother's Day outfit (right)

Figure 7 shows two Tmall banner ads side by side, advertising automobile and Mother's Day outfit. We will use these two ads to analyse the value of interactivity achieved through the framework we proposed as an extension of the carnival.

Ideational function. At the top of the screenshots (Figure 7), above the banner ads, there are three 
interactive signs/sites from left to right. Syntagmatically, the top left places a QR code and AR (augmented reality) scanner with two Chinese characters 扫码 (to scan code); paradigmatically, touching or tapping the scanner activates the QR code scanner to direct consumers to anything that can be scanned. Scanned items can be a product image online, or a physical product with coded information on its packaging. In the middle of the top bar, a lens symbol is presented. It is often used to represent a 'search' function. It also uses text to advertise 'hero' goods placed in front of many goods lined up for consumption, just as supermarkets do in their physical stores. The ad on the left displays ‘穿小白鞋 来一场和青春的约会' (wear the little white shoes on a date). The 'little white shoes' are 'hero' goods that went viral online and have gained popularity among Chinese youth. The ad on the right promotes a newly released model from the Chinese smartphone manufacturer Huawei, model Honour5c, and announces its exclusive debut/release on Tmall. Following this text, the lens syntagmatically presents an additional camera symbol. Paradigmatically, this function (called 'miaopai') allows consumers to take a picture of any desirable good they see and search for. It can bring up search results with similar or even identical goods on Tmall. Alibaba has incorporated this function on various video platforms to form strategic partnerships (for the camera symbol and 'search with picture' function, see Figure 8). Of course, the search box can be filled through typing, which is a conventional interactive affordance. In Figure 8, on the top right corner, a text box symbol is presented syntagmatically. Clicking or tapping it, paradigmatically, opens up a new page with the Tmall notification box, filled with various messages (currently four messages). The message box may include, retargeted promotions (based on consumers' search history and previous purchasing behaviour), direct marketing messages pushed by official shops that consumers follow, social media chats with friends on Tmall and notifications of delivery tracking numbers. 


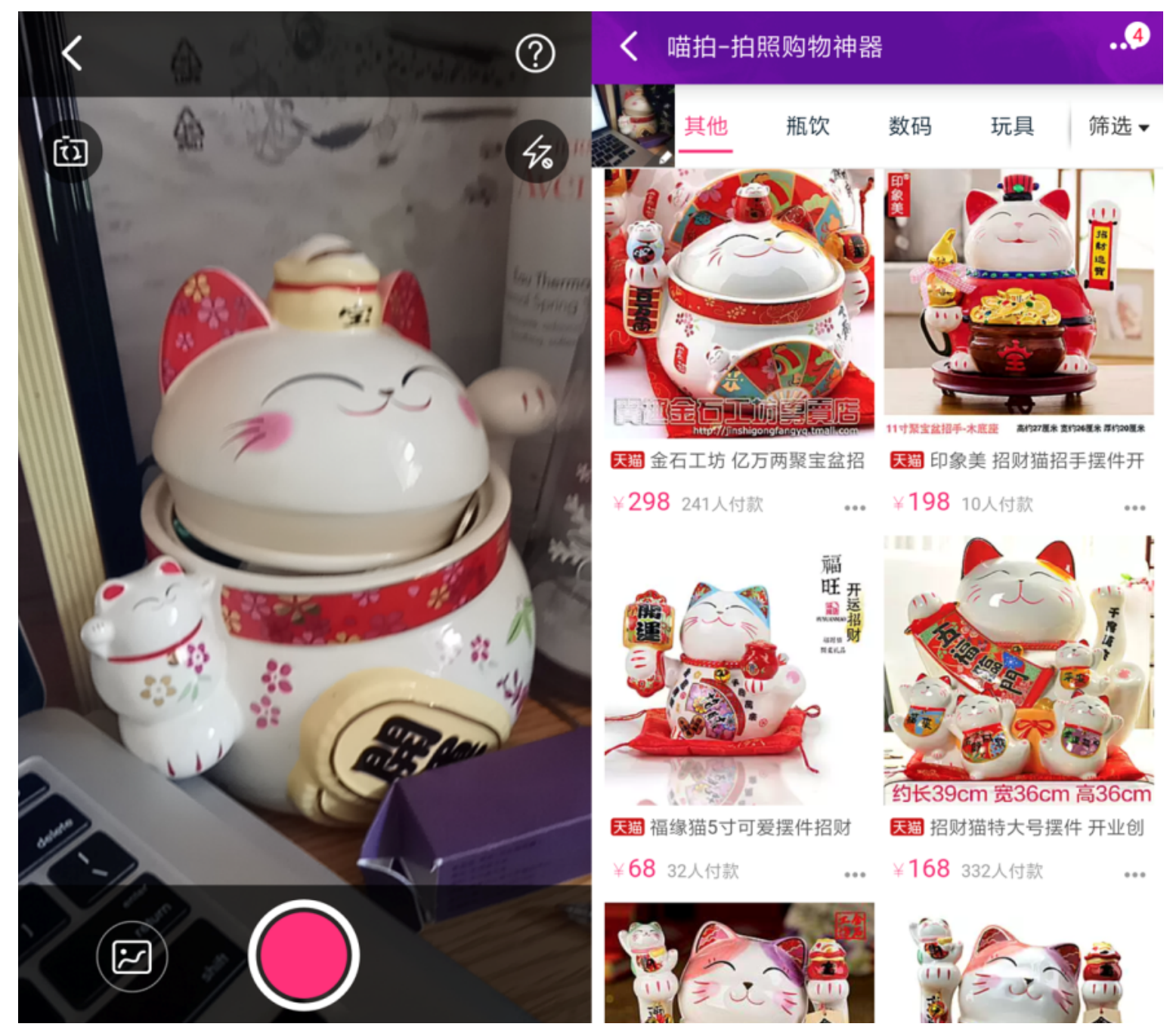

Figure 8. Built-in miaopai function located within the search box on Tmall banner ads

Within the banner ads, the ideational function is embodied in clickable/touchable links and icons, such as ‘去抢购 go' (to snap up and go), “火速下订” (order now) with a symbol of an arrow, and ‘美 妈新衣满减包邮 更有好礼相送 >>' (New outfits for pretty moms, in addition to free delivery if a purchase exceeds a certain amount, and other nice gifts). Syntagmatically, these texts and symbols all send similar information to encourage spending as in the Double 11 Carnival. Paradigmatically, clicking or tapping on the ads or the 'go' sign, the arrow, or ' $>>$ ' directs consumers to the relevant Tmall product page. In addition, below the banner ads there are ten rectangles with rounded corners. They present ten other services in the Alibaba ecosystem, including e-payment, fans' party (social media function), free gift samples, as well as coupons and memberships, to name just a few.

Ideationally, the landing page of the Tmall app is dense with interactive signs and sites. Syntagmatically, it incorporates various formats such as dynamic elements (flash), symbols, icons, still images and writing. Paradigmatically, it requires possible actions such as clicking, tapping, 
scanning, typing and taking photos. These interactive actions have greater effects than mere reception of the text and also enable access to new texts and sites. The interaction that consumers can have does not necessarily limit to banner ads themselves. The interactive affordances achieve hypertexuality by linking to and opening up new sites in a variety of ways, such as sliding for new images (dots placed at the bottom left of the banner ads), page changes and pop-up windows.

Interpersonal function. The interpersonal function is orchestrated at an organisational (meso) level through technology-enabled affordances. These include search engine optimisation (SEO) and algorithm-based retargeted ads. However, due to limited space, our focus is on the front-end, including the graphic design and the intended affordances with which the interactive icons are embedded ${ }^{1}$.

Syntagmatically, the icons and symbols on top of the banner ads signal to consumers that Tmall is allpurpose and ubiquitous: consumers can buy everything on it and socialise with friends on it. According to Adami (2015), such interactive functions are expected by consumers (perceived interactivity) and once provided, they create a complex dynamism to augment consumers' experience. As a B2C e-commerce platform, Tmall uses other features such as colour palette and modular layout to differentiate itself from the $\mathrm{C} 2 \mathrm{C}$ Taobao platform, which is seen as filled with counterfeits. Tmall aims to build a different brand image. By collaborating with well-known brands home and aboard, Tmall aims to emphasise professionalism and its official status. This carefully constructed identity can be seen from the multimodal resources it uses. The richness, coolness (enabled with up-to-date technology) and exclusiveness are constructed from both the syntagmatic and paradigmatic dimensions, converging on various interactive and non-interactive modalities. Banner ads are created to show consumers what products and services are on offer with an 'official tone', for example, through branded trademarks.

Paradigmatically, the interpersonal function can be achieved through a range of affordances and interactive functions to be activated. However, this interactivity is controlled and restrained to a certain degree. The modality configuration of the banner ads uses more images than text, exemplified by dynamic and still images, as well as icons. These images and icons are used to present both products and interactivity signifiers. Such configurations are intended to encourage consumer actions to achieve selective effects - not to allow consumers to create and manipulate ads or products (as they can to a certain degree on Taobao as shop owners) - but to provide mere access to further pages within Tmall, selling more products and services provided by certified brands (strategic partners). Even the social media function is limited to actions such as providing reviews, posting pictures after purchase and befriending shop owners or other buyers within the Tmall platform. Therefore, the interactive affordances are enhanced, but only to a certain degree. There is a clear directionality (selfreferencing) in the realisation of the interpersonal function, recursive within the larger Alibaba 
ecosystem. In addition, Tmall not only shapes its own professional, cool, official and exclusive image, but also projects a controlled 'identity value' to consumers who visit the site, with a preference for visual modalities (signs and sites to be activated) over conventional texts (deemed non-interactive).

Textual function. Syntagmatically, the design and positioning of the interactive functions follow Tmall's conventions, cultivating a habit and particular aesthetic experience for its consumers. Once consumers open the Tmall app, they will expect the same layout and process that they experience in a physical store. In addition, the banner ads are placed in a very salient position (at eye level) and at the top of the landing page. There is also a sliding function so that consumers can switch between the ads (the dots sign). Overall, the banner ads allow for a level of manipulation, enhancing their interactive aesthetics as a whole. Paradigmatically, the transformation process marked by the before-after (interaction by clicking or hovering over) relationship between the signs and sites is quite cohesive and limited in scope, because Tmall does not allow third-party expansion. Whether it involves scanning, searching or redirecting, the interactive affordances are restrained within Tmall and are connected with purchasing. In this sense, the carnival celebrated by Tmall has little to do with sociality or life uplifting. Rather, it is all about purchasing under the disguise of gamification and festive mood. For example, the coupons and red envelopes with deadlines (the icon of countdown) create interactive stimuli for consumers to click and pay, timely. Otherwise, consumers may lose such an opportunity to get a bargain.

Combining a detailed multimodal analysis and social semiotic study of the meanings of the banner ads (micro), Tmall platform design (meso) and wider Chinese society (macro), we have demonstrated that banner ads and Tmall have been constructed as commodities, and at the same time, have commodified the interactive and social sphere (social media functions to share pictures and reviews on purchased products and services). In doing so, we have shown that a communicative consumerism is underway in contemporary China. In particular, Bakhtin's notion of carnivalesque has been distorted and captured by Tmall, a consumerist machine, despite the fact that it provides convenient online shopping and social experiences at a relatively low cost. Through a tentative analysis of both the interactive and non-interactive function of Tmall banner ads, we have presented a picture of the development of Tmall banner ads as both signs and sites. Equipped with the framework of the two dimensions, the textual and visual modalities (text, colour, typography and imagery) are analysed as the initial state, followed by the interactivity as 'what happens' if they are activated - a before-after relationship within a becoming process.

\section{Conclusion}

Based on the analysis of banner ads on Tmall on both the syntagmatic and paradigmatic dimensions, we find that the ads have been incorporated into a gamification design to encourage consumers to spend more and buy things they may not need, even after the Double 11 Carnival. The banner ads 
appeared during the carnival are largely the same as those used to motivate everyday consumption on Tmall, however, with the former displaying intensified modalities to encourage consumers to spend within a short timeframe. The intensified modalities include the use of festive colours and gamification design (red envelope campaigns), and more importantly, an emphasises on 'low cost' such as, special discounts, coupons and free delivery services. Combined with English words such as 'buy now' and 'go', terms such as 低价 (low price), 特价 (on sale) and 抢 (snap up), the intentionality of purchasing (panic and scare of losing a bargain) is intensified through such gamification design. The message of 'there will be no chance to get the goods at such a low price later (after the carnival)!' is expressed explicitly through the aforementioned terms and icons. The reason why we see the carnival has been extended to non-carnival, everyday consumption is because coupons and red envelopes (hongbao) are becoming a norm for most Tmall shops. The banner ads and coupons with clickable and touchable links are directly linked to a consumer's Tmall account, which displays discounts, special deals and 'buy 1 get 1 free' services. In addition, if one's purchase has exceeded a certain amount of money, a free gift will be sent with the delivery or the shipping fee will be waived. These discourses and visual construction (afforded by interactivity) are primarily monetary stimuli. Such stimuli work particularly well on Tmall because consumers are attracted by cheap, quick and convenient shopping and delivery services, again, on a daily basis. The Double 11 Carnival for singles is an important case in focus, extending its reach even after the carnival. It has transformed from a business campaign to a cultural phenomenon in China. In the Chinese context, the ten-year carnivals run by Tmall have creatively obscured Bakhtin's notion of carnivalesque as nonviolence resistance. The term lost its critical connotations since consumers' aim is no longer to resist and dissolve control and suppression by a capitalist and consumerist logic. Rather, such carnival celebration is now captured by consumerism and used to exhort consumers to consume more, so consumers will continue to be controlled.

In sum, our approach is informed by existing studies but provides original insights in two ways. First, it departs from the social semiotic approach and combines both the textual and visual analysis following the VG framework at a more detailed level. In addition, we have conducted much-needed testing of the tentative framework developed by Adami (2015: 150), a nuanced development focusing on the 'meaning-potential of interactive sites/signs' (however, her analysis is primarily focused on interactivity). Therefore, our approach is explicitly multimodal, taking the textual, visual and interactive resources (the trifold convergence) into consideration to examine new phenomena in a digital and multimedia environment, further contributing to the research on multimodal and textual analyses. Our study will be helpful for scholars in fields as diverse as media and communications, advertising and marketing, and visual communication design, where multimodal and textual analyses are of great importance. 
However, our study does have limitations. Firstly, gamification design is not unique on Tmall, however, as an e-commerce monopoly Tmall has the clout and financial backup that is incomparable by other platforms. The carnival spectacle orchestrated on Tmall is unique as it is one of the only few platforms that can generate such media attention and consumer engagement. Secondly, compared with the rich texts investigated in media studies, examples of audio and video are missing in our framework. As audio and video are being employed in banner ads or in advertising more generally, the use of such media should be incorporated and addressed in future research. Thirdly, as discussed in the literature review, traditional semiotic study and SFL are fundamentally functionalist. Our approach is justified in linguistic studies in that the (intended) meaning-making process is worth investigation in its own right. As an analytical process, deconstruction can yield valuable insights. Finally, similar studies on other platforms and novel technologies such as artificial intelligence are needed to test the proposed model in different cultural and technological contexts from a comparative perspective. These parallel paradigms and approaches will challenge and open up interesting new spaces for future discussion.

\section{References}

Adami, E. (2015) What's in a click? A social semiotic framework for the multimodal analysis of website interactivity. Visual Communication, 14(2), 133-153.

Aiello, G and Dickinson, G. (2014) Beyond authenticity: A visual-material analysis of locality in the global redesign of Starbucks stores. Visual Communication, 13(3), 303-321.

Alibaba. (2017a) Our businesses. Available at: http://alibabagroup.com/en/about/businesses. (accessed September 2017).

Alibaba. (2017b) Alibaba Group Announces June Quarter 2017 Results. Alibaba Group. Available at: http://alibabagroup.com/en/news/press pdf/p170817.pdf. (accessed September 2017).

Alizila. (2018) Alibaba's 11.11 outstrips biggest US shopping holiday. Available at: https://www.alizila.com/alibabas-11-11-outstrips-biggest-us-shopping-holiday/ (accessed December 2018).

Bakhtin, M. (1984) Rabelais and his World (Trans Iswolsky H). Bloomington: Indiana University Press.

Boeriis, M. and Holsanova, J. (2012) Tracking visual segmentation: connecting semiotic and cognitive perspectives. Visual Communication, 11(3), 259-281.

Chen, A. and Machin, D. (2014) The local and the global in the visual design of a Chinese women's lifestyle magazine: A multimodal critical discourse approach. Visual Communication, 13(3), 287-301.

Chen, J. (2017) All you need to know about Tmall's Double 11 marketing campagin. Available at: https://www.digitaling.com/articles/41568.html. (accessed December 2018).

Chen, S. (2016) Selling the environment: Green marketing discourse in China's automobile advertising. Discourse, Context and Media, 12, 11-19.

Chik, A. and Vásque, C. (2017) A comparative multimodal analysis of restaurant reviews from two geographical contexts. Visual Communication, 16(1), 3-26.

CIW. (2018) Top cross-border import e-commerce platforms in China in Q1 2018. China Internet Watch. Available at: https://www.chinainternetwatch.com/tag/tmall-global/ (accessed August 2018).

Feng, D. and Wignell, P. (2011) Intertextual voices and engagement in TV advertisements. Visual Communication, 10(4), 565-588. 
Frith J (2013) Turning life into a game: foursquare, gamification, and personal mobility. Mobile Media \& Communication, 1(2), 248-262.

Gidlöf, K., Holmberg, N. and Sandberg, H. (2012) The use of eye-tracking and retrospective interviews to study teenagers' exposure to online advertising. Visual Communication, 11(3), 329-345.

Grumbein, A. and Goodman, J.R. (2015) Pretty as a website: Examining aesthetics on nonsurgical cosmetic procedure websites. Visual Communication, 14(4), 485-523.

Halliday, M.A.K. (1978) Language as social semiotic: The social interpretation of language and meaning, Baltimore: University Park Pres.

Halliday, M.A.K. (1994) An Introduction to Functional Grammar, London: Arnold.

He, X. (2017) Transitivity of kinetic typography: Theory and application to a case study of a public service advertisement. Visual Communication, 16(2), 165-194.

Holsanova, J. (2012) New methods for studying visual communication and multimodal integration. Visual Communication, 11(3), 251-257.

Hulme, A. (2014) The Changing Landscape of China's Consumerism, Oxford, UK: Chandos Publishing.

Jessen, I.B. and Graakjær, N.J. (2013) Cross-media communication in advertising: Exploring multimodal connections between television commercials and websites. Visual Communication, 12(4), 437-458.

Kress, G.R. and Van Leeuwen, T. (2001) Multimodal Discourse: The Modes and Media of Contemporary Communication Discourse, London: Arnold.

Kress, G.R. and Van Leeuwen, T. (2006) Reading Images: The Grammar of Visual Design, London: Routledge.

Lemke, J.L. (2002) Travels in hypermodality. Visual Communication, 1(3), 299-325.

Lick, E. (2015) Print advertising in anglophone and francophone Canada from a critical discourse analytical point of view: Establishing different relations between the producer and viewer of advertisement images. Visual Communication, 14(2), 221-241.

Meng, B. and Huang, Y. (2017) Patriarchal capitalism with Chinese characteristics: Gendered discourse of 'Double Eleven' shopping festival, Cultural Studies, 31(5), 659-684.

McVee, M. and Carse, C. (2016) A multimodal analysis of storyline in 'The Chinese Professor' political advertisement: Narrative construction and positioning in economic hard times. Visual Communication, 15(4), 403-427.

MGI. (2013) China's e-tail revolution: online shopping as a catalyst for growth. McKinsey Global Institute. Available at: www.mckinsey.com/.../China e.../MGI_China_e-tailing_Full_report. (accessed September 2017).

O’Halloran, K.L., Tan, S., Smith, B.A., et al. (2011) Multimodal analysis within an interactive so ware environment: Critical discourse perspective. Critical Discourse Studies, 8(2), 109-125.

Parag D., Potia, A. and Salsberg, B. (2013) Retail 4.0: The future of retail grocery in a digital world. Singapore: McKinsey \& Company.

Parvinen, P., Oinas-Kukkonen, H. and Kaptein, M. (2015) E-selling: A new avenue of research for service design and online engagement. Electronic Commerce Research and Applications, 14, 214-221.

People's Daily. (2018). Domestic consumption expansion was brought up after three years, what message does it send? Worker.cn. Available at: http://finance.workercn.cn/33004/201811/28/181128092716902.shtml. (accessed December 2018).

Da Conceição Pereira, A. (2016) Contrasting (power of) visual and textual discourses in art studies: A critical perspective. Visual Communication, 15(1), 33-53.

Prendergast, M. (2019) Political cartoons as carnivalesque: a multimodal discourse analysis of Argentina's Humor Registrado magazine. Social Semiotics, 29(1), 45-67.

Rofel, L. (2007) Desiring China: experiments in neoliberalism, sexuality, and public culture, Durham; London: Duke University Press.

Sifaki, E. and Papadopoulou, M. (2015) Advertising modern art: A semiotic analysis of posters used to communicate about the Turner Prize award. Visual Communication, 14(4), 457-484. 
Tan, S. (2010) Modelling engagement in a web-based advertising campaign. Visual Communication, 9(1), 91-115.

Thomas, M. (2014) Evidence and circularity in multimodal discourse analysis. Visual Communication, 13(2), 163-189.

Unsworth, L. (2015) Persuasive narratives: evaluative images in picture books and animated movies. Visual Communication, 14(1), 73-96.

Urban, G. (1981) Review of language as social semiotic: The social interpretation of language and meaning by M.A.K. Halliday. American Anthropologist, 83(3), 659-661.

Van Dijk, T.A. (1993) Principles of critical discourse analysis. Discourse \& Society, 4, 249-283.

Van Leeuween, T. (2011) Language of Colour: An Introduction. London: Routledge.

Wagner, K. (2015) Reading packages: Social semiotics on the shelf. isual Communication, 14(2), 193-220.

Wang, X. (2014) In pursuit of status: the rising consumerism of China's middle class. In: Hulme A (ed) The Changing Landscape of China's Consumerism. Oxford, UK: Chandos Publishing, 122.

White, P. (2010) Grabbing attention: The importance of modal density in advertising. Visual Communication, 9(4), 371-397.

Wong, W.W. (2016) Synthetic personalization of Barack Obama at the 2008 US Democratic National Convention: A social semiotic multimodal analysis of a staged political context. Visual Communication, 15(4), 509-534.

Xu, Z. (2007) Everything is up for trade (G. R. Barmé, Trans.). China Heritage Quarterly. Available at:http://www.chinaheritagequarterly.org/articles.php?searchterm $=018$ tradingheritage.inc\&is $\underline{\text { sue }=018}$. (accessed September 2017).

Zappavigna, M. (2016) Social media photography: Construing subjectivity in Instagram images. Visual Communication, 15(3), 271-292.

\footnotetext{
${ }^{1}$ At the XD2019GoldCoast Conference hosted by the Griffith Centre for Design and Innovation Research, a design director of Alibaba presented how the semiotic analysis we are unpacking (termed as "designer insights") and the aforementioned technology Alibaba is developing have been brought together by designers and data analysts to train their artificial intelligence system to automatically generate banner ads for individual shop owners who do not necessarily have the semiotic skills to create banner ads for their own shops.
}

\section{Notes on contributors}

Zhen Troy Chen, $\mathrm{PhD}$ is Assistant Professor of Communication Studies at Xi'an Jiaotong-Liverpool University. He is also Adjunct Research Fellow of the Griffith Centre for Design and Innovation Research at Griffith University. His research interests are in digital media and advertising, journalism, cultural and creative industries, cultural and media policy, and experience design. His recent research papers have appeared in Journal of Consumer Culture, Ethics and Information Technology, Asian Journal of Women's Studies, Global Media and China.

Ming Cheung, $\mathrm{PhD}$ is Professor of Experience Design and Founding Director of the Griffith Centre for Design and Innovation Research at Griffith University. Her research and professional interests focus on digital design + literacy, health innovation + informatics, and media strategy + impact. To date, she has led more than 30 research and consultancy projects nationally and internationally, produced over 110 peerreviewed outputs, and delivered 65 keynote and invited speeches in the fields of Design, Media and Communications. Her publications have appeared in Social Semiotics, Semiotica, The Design Journal, IEEE Transactions for Professional Communication, Ethics and Information Technology, among others. Prior to joining academia, she had over 10 years of senior management experience in industry. 